UN I TED STATES DEPARTMENT OF THE INTERIOR GEOLOGICAL SURVEY

\begin{abstract}
Assessment of a Prototype Earthquake Prediction Network for Southern California
\end{abstract}

James H. Dieterich 1.

Open-File Report $83-576$

This report is preliminary and has not been reviewed for conformity with $U$. $S$. Geological Survey editorial standards and stratigraphic nomenclature.

1. USGS, Mento Park, Ca. 


\section{ASSESSMENT OF A PROTOTYPE EARTHQUAKE PREDICTION NETWORK \\ FOR SOUTHERN CALIFORNIA}

\section{SUMMARY}

This report presents a rationale for earthquake prediction and outlines the components of a prototype operational earthquake prediction network for southern California. The following points are relevant to such an undertaking:

- Earthquakes are a national problem with all or portions of 39 states lying in regions of moderate or major seismic risk. Catastrophic earthquakes in the United States are inevitable and hold the potential for causing great loss of life and widespread property damage. Such occurrences could have regional impact on public services and national impact on manufacturing, the economy and national defense. Earthquake prediction is a significant and primary means for enhancing the effectiveness of preparedness activities and for mitigating the effects of great earthquakes.

- The southern portion of the San Andreas fault in southern California is widely recognized by earth scientists as having a very high potential for producing a great earthquake within the next few decades. This high probability in conjunction with observations of crustal movements that are anomalous, but of uncertain significance, and a large population at risk indicate that this region is of greatest priority for development of an operational prediction capability.

- Observations worldwide have demonstrated that many damaging earthquakes are preceded by patterns of anomalous phenomena that could be used for predictive purposes. Indeed, damaging earthquakes have been predicted in areas where instruments have been placed for these purposes in China, USSR and Japan. Within the United States substantial progress has been achieved in earthquake prediction and this report represents an initial discussion of the concepts that should be considered in the development and deployment of a prototype operational prediction network in southern California.

- Changes in the state of crustal deformation at or near earthquake producing faults are of primary importance for assessing long-term earthquake potential and are recognized as the primary cause of short-term precursory anomalies. Measurements of the state of crustal deformation through an integrated program of continuous instrumental monitoring and intermittant precise surveys constitute an essential element of an operational prediction network. An operational prediction network for the southern San Andreas fault requires a minimum of thirty-five instrument clusters in conjunction with very precise local and regional survey measurements. 
Background seismic activity, consisting primarily of micro-earthquakes, can provide a detailed three-dimensional picture of fault structures and the state of strain release processes on these faults. Changes in seismicity patterns provide a basis for recognition of premonitory phenomena, including foreshocks to a great earthquake and regional changes in the mode of strain release. For these reasons a modern seismographic network compliments the capabilities and functions of a crustal deformation network and is a necessary component of an operational prediction system. The network could, with additional development, provide an automated notification that a large earthquake is in progress alerting critical facilities up to 30 seconds in advance of strong ground shaking.

- The time between the occurrence of short-term anomalies and damaging earthquakes may be several days to an hour or less, necessitating rapid and reliable processing of large volumes of data. Therefore, essential components of an operational prediction system are a reliable data telemetry system and a dedicated data analysis facility with appropriate capability for prompt or on-line processing of network data. A critical yet uncertain element which will determine the success of an operational network pertains to the evaluation of the processed data. Evaluation criteria and decision making procedures must be well-planned and geared for rapid response at the time the network becomes fully operational.

- Preparedness and mitigation planning to effectively respond to and utilize earthquake prediction information should proceed in parallel with the development of the prototype operational prediction network. 


\section{INTRODUCTION}

An objective of the Earthquake Hazards Reduction Act of 1977 (P. L. 95-124) is the implementation in all areas of high or moderate seismic risk, of a system (including personnel, technology, and procedures) for predicting damaging earthquakes. To accomplish this the Geological Survey conducts earthquake prediction research through a program that involves Government scientists, interacts with foreign earthquake prediction programs, and provides support for earthquake prediction studies in the academic community and private sector. The goal of the research has been to develop an operational earthquake prediction capability through the collection of baseline data in areas of seismic risk, identification of phenomena precursory to damaging earthquakes, development of a fundamental understanding of the physical laws governing the earthquake cycle, improvement. of measurement and analysis techniques and conduct of site-specific prediction experiments.

A prototype operational prediction effort is a necessary evolutionary step toward the goal of an earthquake prediction capability in the Nation. This report outlines a program for undertaking the development of a prototype network in southern California. The plans summarized here evolved in large part from monthly prediction data review meetings (in 1981 and 1982), semi-annual southern California prediction data reviews (1980 through 1982) and a major program review held in early 1982. The latter meetings involved scientists from the U.S. Geological Survey, Universities, State Governments and consulting companies.

This report is an initial response to a request by the Senate Committee on Commerce, Science and Transportation to develop a detailed program plan for completion of a prototype prediction system by fiscal year 1988. The intent of this report is to provide information to assist the decision making processes pertaining to a prototype operational network and to serve as a framework for detailed planning studies. Detailed studies for design and planning of a prototype network are being conducted in fiscal year 1983 utilizing funds designated for that purpose.

For planning purposes a five year development and implementation schedule has been used for this report. The schedules could be accelerated or slowed somewhat without major impact on these plans. However, attainment of an operational capability in three years or less, while possible, would probably require a more costly program with a somewhat different implementation plan. If such a development effort is undertaken, it is desirable to complete it promptly, in four or five years, because of the potential immediacy of the hazard and because the network will need a period of operation to collect data before it can become effective. Conservative estimates, discussed below, yield a 48 percent probability that a large earthquake in southern California will occur prior to the end of FY1988, the target date for completion of the network. In addition, because operational costs accumulate prior to operational readiness of the system, a lengthy development time is probably not optimally cost effective. 


\section{THE PROBLEM}

The objective of operational prediction is to issue timely warnings for 1 arge earthquakes such as those that occurred in California in 1857, 1872, and 1906; in the mid-continent area in 1811/1812; in the eastern United States in 1886; in Alaska in 1964; and in Hawaij in 1868 and 1975. The future will inevitably see the occurrence of comparable earthquakes in various areas of the United States. Indeed, all or portions of 39 states are in regions of moderate or major seismic risk (Algermissen, et al., 1983)

Population growth and industrial development, concentrated in areas of earthquake hazard, have created a situation in which casualties and property losses for some expected future earthquakes will greatly exceed those of any. historic earthquake disaster in the United States. A large earthquake in a heavily populated area can be expected to result in regional disruption of public services, transportation systems and interruption of communications. In addition, a disaster on the scale possible for a great (M8) southern California earthquake may have consequences beyond the immediate casualties and property losses caused by the earthquake. Damage to transportation links and to key industrial facilities concentrated in an affected region could have an impact on the Nation as a whole including economic activity and defense preparedness. The magnitude of the problem in California is addressed in the report prepared by the ad hoc committee on Assessment of Consequences and Preparedness for a Major California Earthquake (FEMA Report, 1980). The report states: "Because of the large concentration of population and industry, the impact of such an earthquake would surpass those of any natural disaster thus far experienced by the Nation. Indeed, the United States has not suffered any disaster of this magnitude in its own territory since the Civil War."

Earthquake prediction is a primary means for enhancing the effectiveness of disaster planning and preparedness activities and for mitigating the effects of an earthquake. Earthquake predictions have the potential for greatly reducing casualties (estimated losses up to 14,000 dead and 55,000 hospitalized for a southern San Andreas event, FEMA Report, 1980) and for reducing loss to contents of buildings ( 6 billion dollars for a southern San Andreas event, FEMA Report, 1980). The value of an earthquake prediction in reducing losses to structures (11 billion dollars for a southern San Andreas event, FEMA Report, 1980) is probably much less. However, some reductions of structural losses due to indirect causes such as fires could be realized by a successful prediction.

\section{CURRENT EARTHQUAKE POTENTIAL IN SOUTHERN CALIFORNIA}

The geologic record gives unambiguous evidence that the great southern San Andreas earthquake of 1857 is appropriately regarded as simply the most recent event in a continuously repeating earthquake cycle. The cycle consists of slow straining of the crust to a critical state followed by sudden strain release when a fault slips during an earthquake. A primary consideration in assessing the need to proceed with the development of a prototype operational system in 
southern California is the probability that the next earthquake in the cycle will occur in the near future: This question is closely tied to the length and regularity of the cycles for large earthquakes in southern California. Long cycles with unpredictably variable inter-event times would provide little opportunity for capturing a damaging earthquake in a reasonable period of time and might result in an unprofitably long wait for the target event to occur. On the other hand, if the cycles are relatively short or have roughly predictable durations, then intensive monitoring efforts may be timed to coincide with the time of maximum likelihood for the earthquake to occur. A sizeable body of evidence indicates that the latter situation currently exists for the southern San Andreas fault and that it is the most appropriate area to consider for development of an intensive operational monitoring effort.

Several independent lines of evidence indicate that the southern San Andreas fault is capable of generating one or more major earthquakes in the near future.

The San Andreas fault system is the boundary between two of the several great mobile plates that make up the earth's crust. Worldwide there has been considerable success in long-term forecasting of great earthquakes along plate boundaries using the seismic gap concept. This method of evaluation is based on the concept that inexorable differential motion of crustal plates leads to strain accumulation along plate margins that in turn causes earthquakes when the strain reaches the critical state for fault slip. A seismic gap is a segment of a plate margin where no large earthquakes have occurred for a long interval of time and therefore strain accumulation is assumed to be large and capable of generating an earthquake. In the period from 1968 through 1980 the $10 c$ ations of 13 major earthquakes of magnitude greater than 7.5 were successfully forecast by this method (Nishenko and McCann, 1981). Because the southern San Andreas fault has not experienced a great earthquake in over 100 years this section has been designated as a category 1 seismic gap (the most critical designation) and the northern San Andreas fault which was the site of the great 1906 earthquake is a category 2 seismic gap (less critical than category 1, but nonetheless considered capable of producing a major earthquake).

The designation of the southern San Andreas fault as a mature seismic gap is supported by analysis of patterns of occurrence of lesser earthquakes in the regions of the 1857 and 1906 earthquakes. Seismicity patterns in those areas from the 1800s to the present show cyclical changes that follow the cyclical pattern of strain accumulation and fault slip for great earthquakes (Mogi, 1981; Ellsworth, et al., 1981). The pattern consists of relatively high rates of seismicity, including numerous earthquakes of magnitude greater than 5.5, before the great earthquakes; the usual cycle of aftershocks following the great earthquakes, which decay to a very low background level with few earthquakes magnitude greater than 5.5; and finally a return to a high background rate prior to the next great earthquake. The rates of seismicity in southern California have been high for several decades and appear to be comparable to the seismicity patterns in northern California for the several decades before the 1906 earthquake. In addition, beginning in 1978, the seismicity rates increased dramaticaliy resulting in as much as a fivefold increase in earthquakes of magnitude greater than 5 . 
Also, beginning in 1978 and persisting for approximately 2 years the pattern of crustal straining underwent a distinctly anomalous and widespread change. The significance of these changes is not understood but these observations may indicate crustal straining approaching a near-critical state in which small perturbations can result in rapid and dramatic changes in seismicity.

More quantitative estimates of the current potential for a great earthquake on the southern San Andreas fault have been derived from the historic and geologic record of earthquakes and fault displacements. The long-term average rates of slip obtained from geologic studies, corraborated by measurements of the present rates of crustal straining, provide a measure of the local rate of straining of the crust. This information combined with data for the amount of fault offset in the previous earthquake yield an estimated time required to reaccumulate the strain to return the fault to the critical state that existed immediately prior to the previous event. Also, at some sites, it is possible to obtain dates for historic or prehistoric earthquakes to directly develop empirical data for earthquake recurrence times independent of strain-rate, and fault offset data. Where these different approaches have been checked, consistent results have been obtained. For example, on the very critical Mojave section of the San Andreas fault (from Fort. Tejon to San Bernardino), the displacement/strain rate data and the dates for prehistoric earthquakes yield expected recurrence times of 125 years and 145 years respectively following the 1857 earthquake. Because the latter number is derived utilizing fewer assumptions, it is generally regarded as the most reliable.

Figure 1 shows the preferred region for deployment of the prototype operational prediction network for the southern San Andreas fault system. The network encompasses the regions and fault segments having highest earthquake probability, including all of the 1857 break, the Indio segment of the San Andreas which has not slipped in historic times and a major branch of the San Andreas fault, the San Jacinto fault. The northern limit of the prototype network is the Parkfield section of the San Andreas fault. This section is included because foreshocks for the 1857 earthquake possibly originated in this area and because this section of the fault presently has an exceptionally high probability for generating a magnitude 6 or possibly a magnitude 7 earthquake. The prototype network does not include the region of low probability, but highly dangerous earthquakes on faults in the immediate vicinity of Los Angeles.

Tables 1 and 2 summarize the results of a systematic analysis of available data for earthquake recurrence and fault slip to estimate the current probabilities for the occurrence of damaging earthquakes on specified fault segments (Lindh, 1983). The tables give the cumulative probabilities (percent) that the indicated earthquake will occur sometime within 1,6,10,20, and 30 year intervals beginning at 1/1/83. (The 6-year interval was chosen to show the probability for the occurrence of an event prior to the projected completion of the network.) The analysis statistically models variability in the recurrence times for earthquakes and the effects of increasing strain accumulation with time. Because the crustal strain that causes the earthquakes increases with time, the indicated current probabilities also increase as the expected time of the earthquake approaches. Many potentially hazardous fault segments 


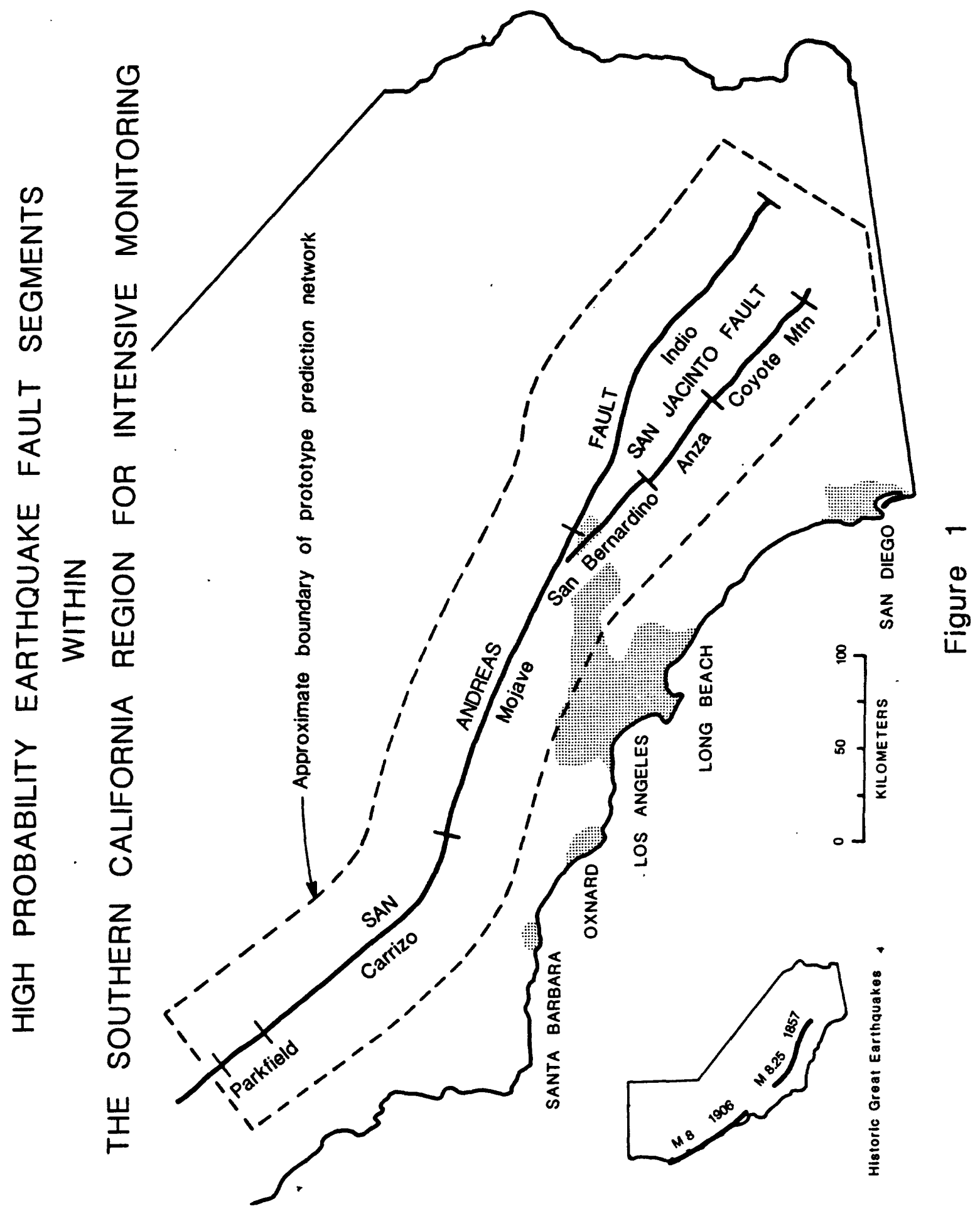


are not treated in this analysis because the data are insufficient. For several reasons, including the omission of some fault segments, conservative assumptions employed in the calculations and the recent occurrences of anomalous phenomena in southern California, the probability estimates in Tables 1 and 2 should be regarded as lower bounds that may significantly underestimate total hazard.

An important result of recent analyses that affects planning for an operational network is that the next great earthquake may not exactly duplicate the 1857 event (Sieh, 1981). It is possible that it will affect either or both the Mojave and Indio segments of the San Andreas fault. As a result, it is imperative to monitor the Carrizo, Mojave and Indio segments of the San Andreas fault.

Estimates of the current cumulative probabilities for individual earthquakes on specific fault segments within the prototype operational network are given in Table 1. For the Mojave section the 145 year mean recurrence interval obtained from geologic dating of previous events has been used. For the Parkfield segment alternate probabilities for a magnitude 6 and for a magnitude 7 event have been calculated.

Total probabilities for the occurrence of an earthquake within different classes of earthquakes are summarized by Table 2. These total probabilities pertain to the occurrence of a single event within a specified category of possible events and are obtained from the data in Table 1. The total cumulative probability for any large earthquake (any event greater than M6.75) within the network is currently 10 percent/year, 69 percent over the next 10 years and 92 percent over the next 20 years. The potential earthquakes that would result in the greatest loss of life and property are those for the Mojave, Indio and Riverside fault segments. The total probabilities for the occurrence of one of those events currently stand at 3.2 percent per year, 31 percent over the next 10 years and 56 percent over the next 20 years.

In summary, Tables 1 and 2 indicate very high current probabilities for occurrence of several 1 arge earthquakes within a geographically restricted area. This region appears to provide the maximum likelihood for capture of a major earthquake event by an operational prediction network within a reasonable interval of time.

\section{READINESS TO UNDERTAKE EARTHQUAKE PREDICTION IN SOUTHERN CALIFORNIA}

Short-term prediction is the principal goal of an operational earthquake prediction network. However, effective evaluation of potential short-term anomalies that might be precursory to an earthquake require a context of longterm baseline data, an understanding of the tectonic framework of a region and long-term assessments for specific earthquakes that are the objectives of the prediction effort. Recognition of this situation has led to a widely held scientific preference in the United States for an earthquake prediction strategy that builds progressively from long-term hazard assessments, through determination of earthquake recurrence intervals for specific regions, to 
TABLE 1

CURRENT PROBABILITIES FOR EXPECTED EVENTS WITHIN

PROTOTYPE PREDICTION NETWORK

(For Intervals Beginning $1 / 1 / 83$ )

Fautt/Segment

Expected

Cumulative Total Probabilities (Yrs)

Magnitude

1

610

20

30

$\begin{array}{lllllll}\text { San Andreas/Parkfield-A } & 6 & 6.2 & 43 & 71 & 98 & 99.99 \\ \text { San Andreas/Parkfield-B } & 7 & 4.6 & 26 & 40 & 66 & 84 \\ \text { San Andreas/Carrizo } & 8 & 0.2 & 1.3 & 2.3 & 5.0 & 8.4 \\ \text { San Andreas/Mojave-145yr } & 7.5-8 & 1.2 & 7.6 & 13 & 26 & 40 \\ \text { San Andreas/Indio } & 7.5-8 & 0.8 & 5.0 & 8.3 & 16 & 24 \\ \text { San Jacinto/R iverside } & 6.75 & 1.2 & 7.6 & 13 & 29 & 46 \\ \text { San Jacinto/Anza } & 6.75 & 2.2 & 13 & 22 & 44 & 63 \\ \text { San Jacinto/Coyote Mtn } & 6.75 & 0.08 & 0.6 & 1.1 & 3.3 & 7.3\end{array}$

TABLE 2

CURRENT TOTAL PROBABILITIES FOR ANY EVENT WITHIN THE LISTED CATEGORY (For Intervals Beginning $1 / 1 / 83$ )

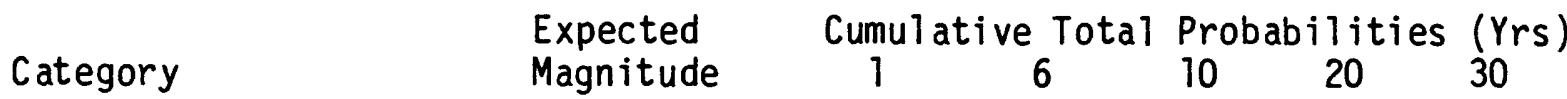

$\begin{array}{lllllll}\text { A } 11 \text { events in Table 1 } & 6-8 & 11 & 61 & 85 & 99.7 & 99.99\end{array}$
using Parkfield-A M6

$\begin{array}{llllll}6.75-8 & 10 & 48 & 69 & 92 & 99\end{array}$

A11 events in Table 1 using Parkfield-B M7

Very large or great events on

$7.75-8$

$2.2 \quad 13$

22

41

58 San Andreas Fault (Carrizo, Mojave, Indio)

Events on San Jacinto Fault 6.75 (Riverside, Anza, Coyote Mtn.)

Events with potential for

$6.75-8$

$3.5 \quad 20$

$33 \quad 62$

80 great damage (Mojave, Riverside, Indio) 
long-term predictions and finally to detailed local monitoring for intermediate-, and short-term predictions in the most critical areas.

A desirable consequence of this strategy is that it leads to optimal application of resources by focusing intensive prediction efforts on the most critical areas which are then targeted for dense instrumentation networks. Less critical regions and regions with poorly understood earthquake potential receive less intensive monitoring to first evaluate the present earthquake potential and to develop baseline data for use in the future as the earthquake potential increases with the passage of time. Additionally, this strategy, by incorporating long-, and intermediate-term forecasting, can give longer lead times to prepare for and coordinate disaster mitigation efforts and response planning to a short-term forecast.

In southern California sufficient studies have been completed to warrant consideration of intensive monitoring for operational prediction studies. Active faults have been delineated utilizing geologic and geophysical means and seismicity patterns on these faults have been recorded for several years. Studies of recurrence intervals for great earthquakes are sufficiently wel1advanced to permit preliminary estimates for long-term predictions, as illustrated by the data in Tables 1 and 2. Seismicity and geophysical monitoring for prediction research purposes in southern California have provided baseline data essential for guiding interpretation of data from an intensive operational monitoring effort. Additionally, the research data collection efforts in southern California have provided the experience required for the selection of the most appropriate measurements to make, installation procedures to use, and data analysis methods to apply.

Although a simple and reliable key to the prediction of damaging earthquakes has not been found, observations in the United States, China, Japan and the USSR have documented complex patterns of intermediate- and short-term anomalous phenomena preceding many earthquakes that could potentially serve as the basis for successful predictions. Indeed it is difficult to find any examples of large earthquakes occurring in well instrumented areas that did not, at least in subsequent analysis, have some type of precursory anomaly. Such observations have led to successful predictions, most notably the prediction of the 1975 Haicheng, China earthquake which is estimated to have saved over 100,000 lives. Data on precursory phenomena are presently inadequate to attempt to estimate the likelihood for a successful prediction in southern California if an operational system is deployed in the near future. However, there exists a firm basis for concluding that at least some damaging earthquakes are predictable utilizing currently available instrumentation and evaluation procedures. In addition, sufficient experience has accumulated worldwide to indicate appropriate measurement and deployment strategies for detecting anomalies and for evaluation of earthquake potential.

Integrated monitoring of earthquakes and crustal strain phenomena constitute the primary observational objectives of the prototype operational network. Within the United States substantial progress has been made in developing the measurement, instrumentation and data processing systems that would be required for operational earthquake prediction. The components of 
the system described below have been tested and are suitable for deployment in a prototype system.

Suitably precise and stable instrumentation systems for continuous strain monitoring has been an obstacle for development of a reliable operational network and the focus of research. Improvements have been achieved and experience gained in instrumentation, field siting techniques, and deployment strategies. It has been found that reliable; high precision monitoring requires measurements over long base-lengths (on the order of $1 \mathrm{~km}$ or more) or in boreholes (at depths of $200 \mathrm{~m}$ or more) to escape deleterious surface noise effects.

Intermittant precise geodetic surveys compliment the capabilities of the continuous strain instrumentation and provide stable and broadscale measurements of changes in crustal strain. The methods of precise geodetic strain monitoring are well advanced. Geodetic strain monitoring has been conducted on a routine basis in southern California for several years, and will provide - high-quality baseline data for an expanded operational effort.

The instrumentation techniques for seismic monitoring are well-established and amenable to rapid deployment. The seismic monitoring effort in California and the data processing system that support it are a major accomplishment of the Earthquake Hazard Reduction Program that is relevant to undertaking operational prediction. In California over 2,000,000 seismograms are routinely analyzed every year to locate approximately 18,000 earthquakes. For operational prediction, the seismic and deformation monitoring instrumentation networks require appropriate robust telemetry that would be resistant to being incapacitated by ground shaking from strong foreshocks.

\section{CRUSTAL STRAIN MONITORING}

Earthquakes occur when deformation of the earth's crust in the vicinity of a fault reaches a critical state and conditions on the fault have evolved to permit rapid release of the accumulated strain by earthquake fault slip. Therefore, changes in the state of crustal strain at or near earthquake producing faults are of primary importance for evaluating long-term earthquake potential. Short-term strain changes at or near faults preparatory to earthquake fault slip are recognized as the principal cause of short-term precursory anomalies.

Empirical evidence suggests that anomalous crustal deformation that precedes damaging earthquakes can take place over large distances (hundreds of kilometers) and long time periods (months to years), as well as over small distances $(1-10 \mathrm{~km})$ and short time periods (hours to days). Unfortunately, it is not yet possible to define in advance either the spatial or temporal scales over which anomalous crustal deformations are likely to occur in the areas of interest. Because of this, a measurement strategy with two distinct components has been adopted. First, detection of broadscale crustal deformation that occurs over long periods of time requires measurements of regional deformation survey networks that have both high accuracy and long term stability. Second, short-term deformation, possibly over smaller scales, necessitates continuous monitoring at numerous observatory sites in the critical areas. 
Measurement of regional deformation survey networks on three month intervals and a minimum of 35 crustal deformation observatories will be required to provide minimally adequate monitoring of the critical areas in southern California. At this level of effort it will be possible to detect small amplitude strain anomalies affecting regions with minimum dimensions of 25-50 kilometers. Increased number of observatories would decrease the threshold of detection.

Knowledge which has been gained of the process of strain accumulation and earthquake strain release defines rather stringent sensitivity and stability requirements for crustal deformation systems. The regional deformation survey networks must have a sensitivity and annual stability of $1.0 \mathrm{~cm}$ over $50 \mathrm{~km}$ baseline (or a strain sensitivity of about $2 \times 10^{-7}$ ). In contrast, because of the low rate of tectonic strain accumulation over periods of a few days to weeks, the crustal deformation observatories need to operate with a strain sensitivity of $1 \times 10-10$ (one part per ten billion), and monthly stability $5 \times 10-8$. The instrumentation described below is capable of achieving these requirements.

\section{CRUSTAL DEFORMATION OBSERVATORIES}

Figure 2 illustrates a crustal deformation observatory currently under test development at Pearblossom, California, on the San Andreas fault. For a southern California prototype prediction network, similar crustal deformation observatories would be deployed at the points shown in Figure 3 . The details of each observatory will be dictated in part by conditions enountered at each site including topography, accessibility, underlying geology and relationship to active faults. In general, each observatory will consist of the following:

Two Color Laser Ranging: By precisely measuring the distance to fixed reflector sites this instrument is capable of monitoring all the various components of the horizonal crustal strain field on a nightly basis in a region of approximately $200 \mathrm{sq} \mathrm{km}$. This instrument has sensitivity of about $1.0 \times 10^{-7}$ on a weekly basis and provides a stable measure of short- to medium-term strain field variations.

Borehole Strain and Tilt: These instruments provide continuous and highly sensitive measures of certain components of the strain field. They do not provide adequate medium- to long-term stability. The instruments are deployed in $200 \mathrm{~m}$ deep boreholes to minimize contamination of the signal by meteorologic disturbances. They are deployed in a redundant mode (two of each type of instrument is installed) because of their extreme sensitivity to localized, non-tectonic disturbances.

In-Situ Stress, Pore Pressure and Geochemistry: At each site a $1 \mathrm{~km}$ deep borehole will be drilled to measure the absolute level of stress in the ground, and to provide a means for monitoring changes in the pressure and composition of subsurface water.

Global Positioning System Satellite Receivers: This developing technology for precise positioning may yield a new system of portable ground receivers 


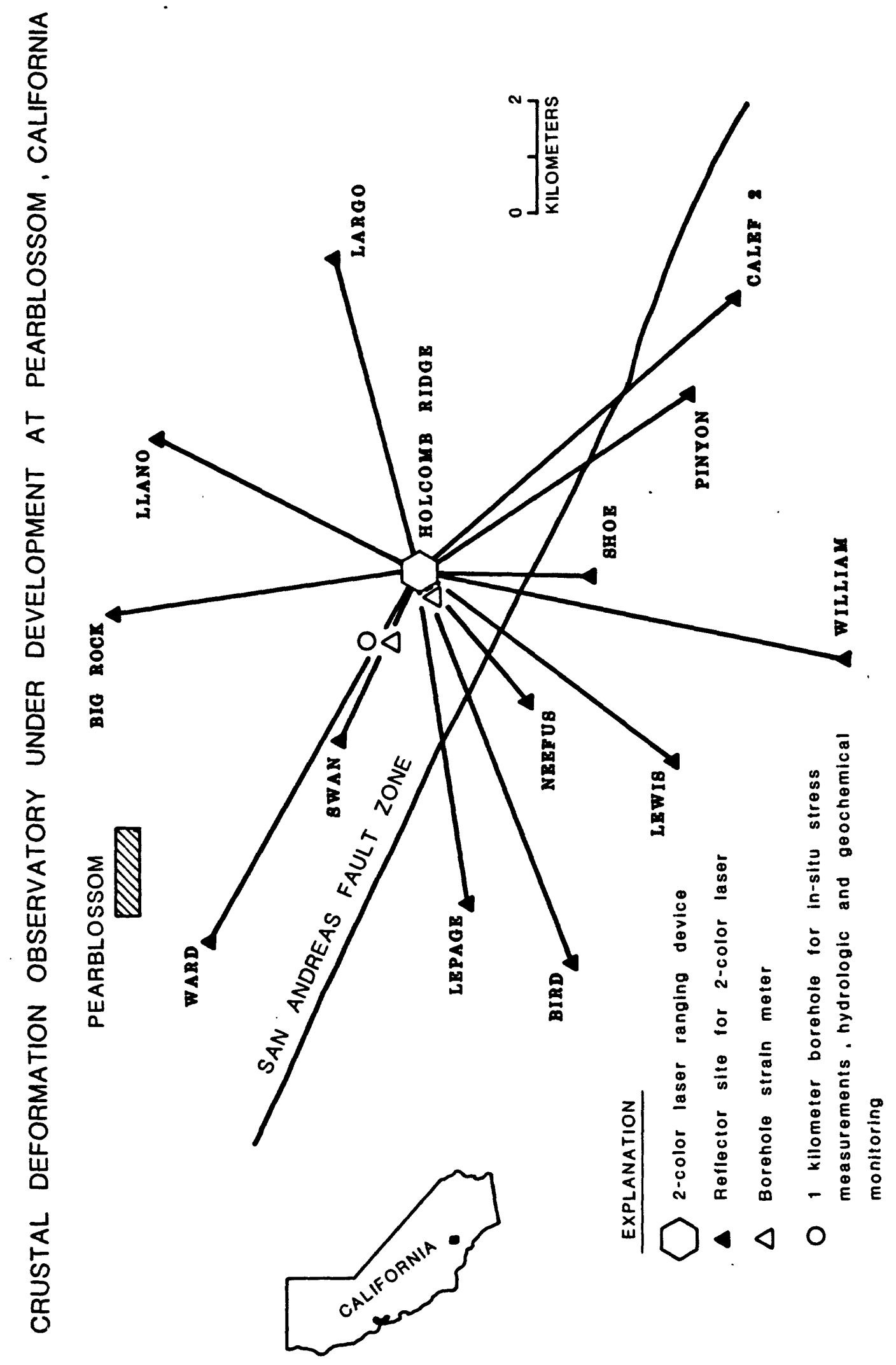




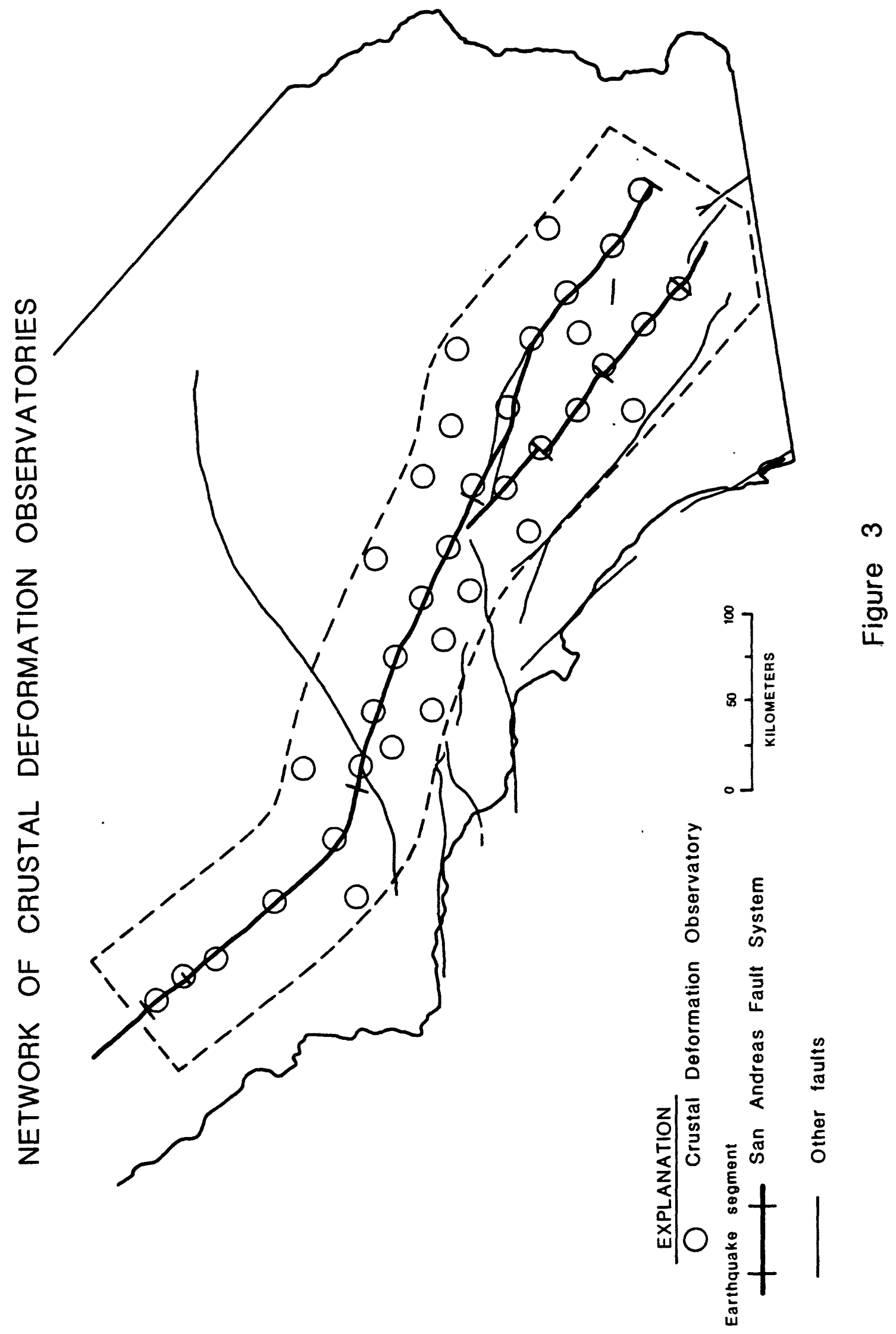


to monitor changes in horizontal position and ground elevation several times per day. If these systems can achieve a sensitivity and annual stability of $1 \mathrm{~cm}$ over a $50 \mathrm{~km}$ base length a very valuable addition to existing strain monitoring methods would be available for earthquake prediction. Portable systems could be available for incorporation into the crustal deformation observatories on a test basis as early as 1985 and for full deployment beginning in 1986 or 1987. Because the necessary precision has not yet been demonstrated, the utilization of this system is included as an option.

Atmospheric Sensors: The sensitivity levels required of the instruments described above necessitate continuous monitoring of atmospheric temperature, pressure, rainfall and relative humidity.

Telemetry: Data from the crustal deformation observatories will be continuously telemetered to the data collection and analysis center described below.

\section{OTHER DEFORMATION MONITOR ING}

At sites inappropriate for fully developed crustal deformation observatories, miscellaneous deformation monitoring activities will be conducted. Measurements will utilize fault creepmeters, well monitoring and instrumental strain monitoring.

\section{REGIONAL MONITOR ING NETWORKS}

The following survey measurements will be made:

Laser Trilateration: These measurements give an extremely stable, largescale view of crustal strain. This method utilizes the travel-time of light between sites to obtain measurements of distance changes caused by crustal straining. An aircraft must fly the line-of-sight during the measurements to correct for the influence of atmospheric temperature, humidity and pressure on the speed of light. Figure 4 illustrates the current trilateration network in southern California. The system of crustal strain networks in the critical areas now being measured annually with geodetic instruments will be continued, but on a more frequent basis (quarterly) and with some augmentation in sparsely covered areas.

High Precision Gravity: A dense network of gravity stations will be surveyed semi-annually to search for regional elevation changes similar to those reported in recent years prior to several large earthquakes, and to tie together the crustal deformation observatories.

First-Order Leveling: In selected areas, level lines will be run to establish elevation control for the gravity measurements. 


\section{SEISMIC NETWORK}

An appropriately configured seismograph network compliments the capabilities of the strain monitoring systems and provides a means for locating active faults and for monitoring the status of strain release processes on those faults. Background seismic activity consists predominantly of microearthquakes with fewer small earthquakes and infrequent moderate earthquakes. Seismic waves generated by earthquakes can be analysed to locate the earthquakes and determine orientations of fault planes, earthquake magnitude and stress changes caused by the earthquakes. This information, evaluated in the context of the historical seismicity and base-line data in a region, provides a detailed means for recognizing regional and long-term changes in the strain release processes occurring on active fault systems. In addition, with rapid processing of seismic data it provides a basis for recognizing immediate premonitory phenomena such as foreshock activity.

The seismic monitoring system currently operating in southern California (Figure 5), jointly operated by the USGS and California Institute of Technology, routinely determines the location and magnitude of approximately 10,000 earthquakes per year. However, the instrumentation and telemetry systems are out of date and are inadequate for routine determination of some critical seismological parameters. In particular, the signal collection systems have too small a dynamic range and too narrow a bandwidth to permit the rapid determination of earthquake source orientation and stress drop, two parameters widely considered to be critical in assessing the significance of individual earthquakes. Cost has been the primary factor preventing the deployment of instrument systems capable of making these additional measurements. An additional limitation of the current seismic monitoring network for operational prediction is vulnerability of the telemetry systems and analysis centers to failure caused by moderate ground shaking. Hence, there is concern that the network could become incapacitated at the most critical time, i.e., during a foreshock sequence to a large earthquake.

Upgrading of the current seismic monitoring network for operational prediction would not require new technological developments. Approximately 50 of the single component narrow-band seismometers now in use would be replaced by broad-band three-component digital seismometers. Some of those instruments would be installed in boreholes at selected deformation monitoring observatories. Robust, dedicated telemetry systems capable of reliable broad-band signal transmission would have to be installed. Implementation schedules are given in Tables 4.

\section{IMMINENT ALERT SYSTEM}

Automated real-time computer systems for processing of seismic data have been developed and field tested in recent years. Reliable, fully automated seismic processing is feasible and permits the real-time assessment of earthquake sequences as they unfold. If properly integrated with an enhanced seismographic network such a system could provide a highly reliable warning that a large earthquake is in progress and that strong shaking is imminent. This possibility is based upon firmly understood physical theory and appears 


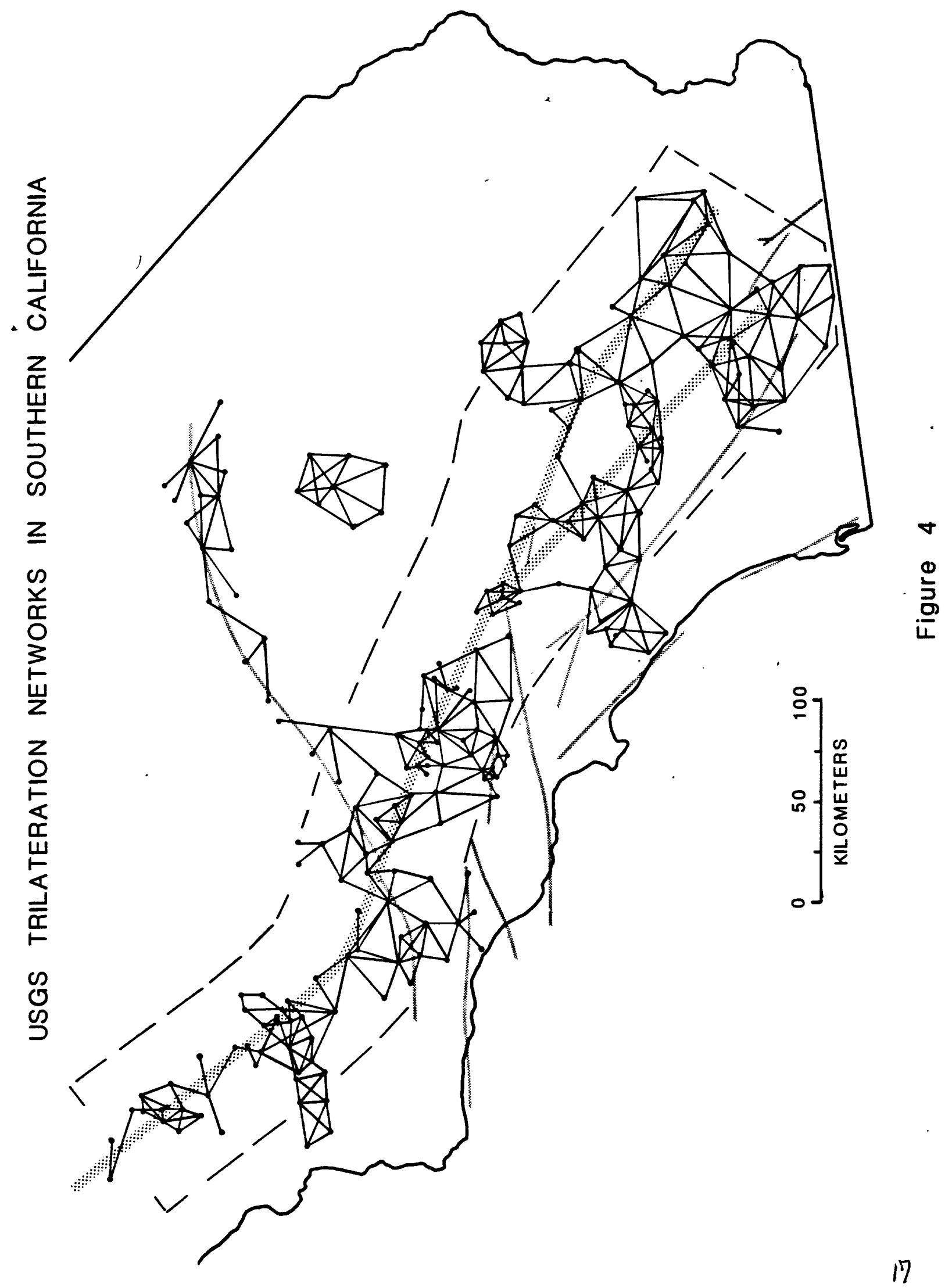


TABLE 3

\section{SCHEDULE FOR CRUSTAL STRAIN MONITORING SYSTEMS}

Fiscal Year 1984:

Crustal Deformation Observatories: Intensive planning and site selection. Complete installation of 5 observatories.

Other Deformation Monitoring Sites: Intensive planning, site selection and installation.

Laser Trilateration: Expand network and begin immediate program of quarterly surveys.

Gravity and Leveling Surveys: Begin program of detailed annual surveys.

Global Positioning System: Participate in inter-agency tests of geodetic receivers.

Fiscal Year 1985:

Crustal Deformation Observatories: Continued planning and site selection. Complete 8 observatories.

Other Deformation Monitoring Sites: Continued planning, site selection and installation.

Laser Trilateration: Quarterly surveys. Gravity and Levelling Surveys: Annual surveys.

GTobal Positioning System: Continue tests and evaluate applicability of these systems for operational prediction network.

Fiscal Year 1986:

Crustal Deformation Observatories: Continued planning and site selection. Complete 8 observatories.

Other Deformation Monitoring Sites: Continued planning, site selection and installation.

Laser Trilateration: Quarterly surveys.

Gravity and Levelling Surveys: Annual surveys.

Global Positioning System (Option): Begin intensive planning development and deployment.

Fiscal Year 1987:

Crustal Deformation Observatories: Minor planning and site selection. Complete installation of 8 observatories.

other Deformation Monitoring Sites: Minor planning and installation.

Laser Trilateration: Quarterly surveys.

Gravity and Levelling Surveys: Annual surveys.

Global Positioning System (Option): Intensive planning, development and deployment.

Fiscal Year 1988:

Crustal Deformation Observatories: Complete installation of 6 observatories. Other Deformation Monitoring Sites: Minor planning and installation. Laser Trilateration: Quarterly surveys. Gravity and Levelling Surveys: Annual surveys. GTobal Positioning System (Option): Complete deployment. 
to be fully capable of providing a valuable alert even if the earthquake has not been predicted.

The basis of an imminent seismic warning system derives from the capability to rapidly and accurately characterize earthquakes at the epicenter utilizing only the initial portion of the earthquake ground motion. Because the elastic waves that cause the major damage in an earthquake travel more slowly than the initial waves, at an average speed of about $2 \mathrm{miles} / \mathrm{sec}(3 \mathrm{~km} / \mathrm{sec})$ there exists a small but highly valuable window of time between the identification of the earthquake (utilizing the most rapidly propagating waves near its source) and the arrival of damaging earthquake waves at sites located some miles from the earthquake. In the case of a repeat of the great southern California earthquake of 1857, it is estimated that the event could be identified more than 30 seconds before the initial strong shaking would reach the metropolitan Los Angeles area. Shorter warning times of a few seconds or more are theoretically possible even at short distances from the epicenter.

The utility and practicality of a fully automated imminent seismic warning system has not been evaluated. However, there are obvious potential applications in which governmental or industrial subscribers could be prepared to take emergency action to protect critical facilities from inevitable earthquake damage even when lead times are very short. Some examples of actions include reconfiguration of the electric power grid to isolate sections with a high likelihood of damage; the safe, preshaking shut down of nuclear reactors; the shutting-in of offshore oil wells before the strong ground motions damage wellhead apparatus; and the isolation of volatile chemicals such as liquid rocket fuel before plumbing or control systems are damaged. Such a system might also significantly reduce risk to the general public in a major earthquake through simple steps such as automatic opening of firehouse doors that might become jammed shut--trapping emergency vehicles inside or by stopping traffic from passing on or beneath critical bridges or overpasses.

Some primitive special purpose systems of this type are in use around the world, but an integrated multi-purpose system has never been developed. An imminent warning system is clearly not earthquake prediction in the usual sense, but it is a practical system that could build from and utilize an earthquake prediction network. In the event that a prototype prediction network is developed the potential benefits for an imminent warning system appear sufficient to warrant consideration of planning studies to evaluate the utility, necessary safeguards and most effective means for operating the system. Development of an automated warning system is listed as an option in Table 4.

\section{DATA CENTER}

The telemetered signals from the observational networks must first be processed and reduced to a useable form then analysed and evaluated to assess the short-term earthquake potential. The data volume and limits on the acceptable time to complete the processing tasks establish constraints on the systems that are to be employed for the network data. The interval between 


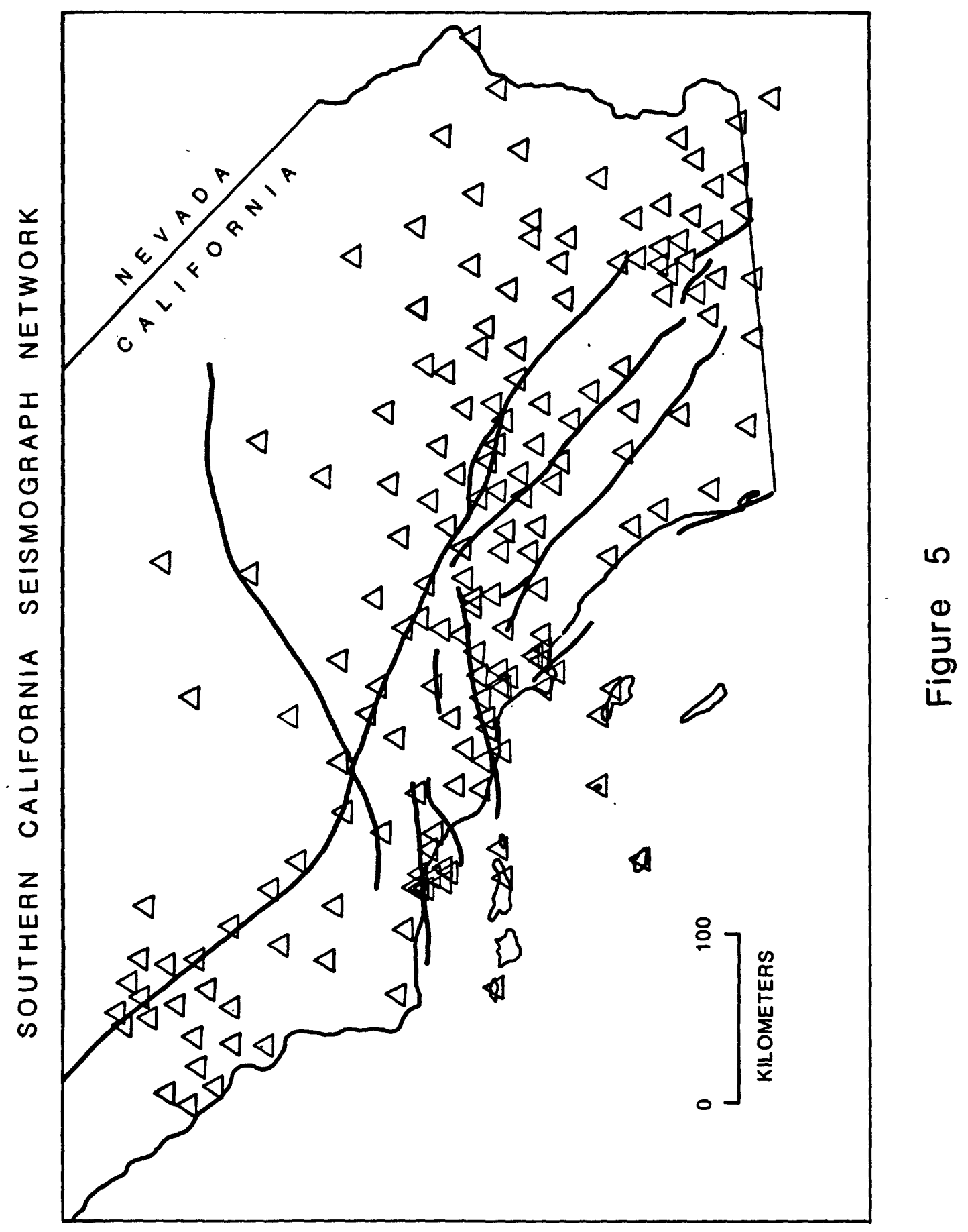




\section{SEISMIC NETWORK IMPLEMENTATION SCHEDULE}

Fiscal Year 1984

Digital Seismometers - Intensive planning. Evaluate systems test initiated in Fiscal Year 1983.

Telemetry - Intensive planning. Evaluate systems test initiated in Fiscal Year 1983. Begin installation.

Warning System (option) - Intensive feasibility planning, preliminary engineering studies.

Fiscal Year 1985

Digital Seismometers - Minor planning and site selection. Install 20 stations.

Telemetry - Intensive installation of hardened telemetry for broadband data transmission.

Warning System (option) - Evaluate feasibility of the system. Intensive engineering and usage planning.

Fiscal Year 1986

Digital Seismometers - Install 20 stations.

Telemetry - Complete installation of hardened telemetry system. Warning System (option) - Continued planning. Begin intensive installation of very hard telemetry; sensor network and processing system.

\section{Fiscal Year 1987}

Digital Seismometers - Install 10 stations.

Telemetry - Operate and maintain.

Warning System (option) - Continued planning. Intensive installation of system.

Fiscal Year 1988

Digital Seismometers - Operate and maintain.

Telemetry - Operate and maintain.

Warning System (option) - Final installation and testing. 
the occurrence of precursory anomalies and an earthquake may be several days to an hour or less. This short time establishes clear needs for immediate processing capabilities and for a central data collection, processing and analysis facility. Those time requirements combined with the 1 arge data rates can be met only by utilizing largely automated systems.

\section{DATA PROCESSING}

The most demanding processing requirements pertain to the seismic data. Large volumes of data must be processed to first detect, then characterize earthquakes as they occur. In addition to finding location and depth, characterization of earthquakes involves analysis of the seismic signals for. determination of earthquake magnitude and source parameters such as stress drop and fault plane orientation. Background rates of seismicity within the area of the prototype network in southern California will require processing of up to $1,000,000$ seismic records to locate and characterize $5,000-10,000$ earthquakes annually. Superimposed on the background activity are occasional seismic crises that may last for several days and consist of swarms of earthquakes. In the more spectacular swarms, such as the January 1983 swarm near Mammoth, California, several thousand earthquakes may occur within a 24 hour period. Hence, at critical times, it should be expected that the processing demand may increase by as much as one hundred times above background rates.

Systems presently in routine operation, developed by the Earthquake Hazards Reduction Program have demonstrated the feasibility for preliminary, fully automated "on-line" processing for earthquake magnitude and location within a few seconds of the occurrence of an earthquake. Final detailed processing to establish a finished research-quality data set presently utilize semi-automated computerized procedures employing analysts at critical steps. For operational prediction with broad-band instrumentation, dedicated systems of this type should be expanded to permit real-time determination of the other source parameters (stress drop and fault orientation). Full editing of the processed data should be completed within one day on a routine basis and within a few minutes for selected earthquakes as circumstances warrant.

Data rates and processing requirements for deformation monitoring are much less demanding than for seismic network data. The principal needs are to convert the telemetered signals to physically scaled and useable records and to place the data in appropriate files for immediate display, review and analysis. These needs $c$ an be met by straight-forward automated processing. Prompt routine review by analysts will be necessary to assure data quality and to annotate the records.

\section{DATA ANALYSIS AND EVALUATION}

The complexity of earthquake processes, the absence of a simple formula for earthquake prediction and the possible short duration between the occurrence of precursory events and an earthquake all focus critically on the interpretation of the processed data. Because of the intrinsic uncertainties 
pertaining to the character or the existence of precursory events that derives from the absence of a data base for previous great southern California earthquakes, evaluation procedures must be broadly based and flexible. The possibility for recording a precursory anomaly, yet misinterpreting its significance, will always exist. There exists a similar possibility for misinterpretation leading to false alarms. Every reasonable step must be taken to reduce these sources of error. Evaluation of the prediction data and decision making procedures will, in all likelihood, be the. weak links in the chain of systems comprising an operational prediction effort. As a result, these aspects of the development effort demand particular emphasis and should be subject to intensive planning during the five-year implementation period.

Analysis and evaluation will require appropriate scientific staff and a dedicated data analysis facility. The principal data functions the facility must be capable of performing are archiving of data, retrieval and display of archive data, geophysical analysis including large-scale modelling and continuous scanning of incoming data for potential precursory changes. Procedures, evaluation criteria, analysis systems and decision making mechanisms must be geared for rapid response at the time an operational network becomes fully operational.

To arrive at continuously up-dated evaluations of the current earthquake potential the processed data must be analysed for geophysical significance, then evaluated in the context of previous observations. The evaluation will utilize region-specific models for earthquake occurrence and general models based upon features common to most earthquakes. Approaches that will be followed include analysis of the data to determine the physical processes that underly changes in observations, comparison of the data against empirical earthquake precursors observed world-wide and computation of probability gains based upon statistical models for the significance of various observational phenomena. Each approach relies on detailed understanding of the seismotectonic framework of the region, comparison of observations to previous records and baseline data and development of models or scenarios for potential implications of geophysical events on an area by area basis.

Table 5 summarizes the development schedules for the data processing and evaluation activities.

\section{PREPAREDNESS PLANNING}

The value of a specific prediction issued by the system described above will depend on actions that are taken in response to issuance of this information. In turn, the ability to respond in an appropriate fashion will critically depend first on a system for efficient dissemenation of the information and secondly, on the state of emergency preparedness at the Federal, State and local government levels. In addition, the general public must be informed and educated in advance of the appropriate actions to take in response to issuance of earthquake prediction information. It is beyond the scope of this report to outline a detailed program for utilization of prediction information. However, an intensive program for detailed planning and preparation at the Federal, State and local levels should proceed in parallel with development of the predictive system. 


\section{SCHEDULE FOR DATA CENTER AND EVALUATION SYSTEM}

Fiscal Year 84

Data Processing Systems: Intensive planning and development of a dedicated processing facil ity.

Data Analysis: Intensive $p l a n n i n g$ and development of a dedicated data storage, retrieval and analys is facility. Begin a continuing program for developing rapid analysis procedures and systems. Begin a continuing program of research on data collected by the networks emphasizing underlying short- to long-term geophysical processes and evaluation of data quality.

Forecasting and Evaluation: Begin a continuing program for development of short-term prediction methodologies and for geological studies to refine and update long-term probability assessments. Intensive $\mathrm{planning}$ to establish the decision-making structure and formation of the group responsible for developing forecasts.

\section{Fiscal Year 85}

Data Processing Systems: Continued intensive development of facility. Data Analysis: Continued intensive development of facility and research.

Forecasting and Evaluation: Continuing activities.

Fiscal Year 86

Data Processing Systems: Complete major facility systems. Continue on-going programs.

Data Analysis: Complete major facility systems. Continue on-going programs.

Forecasting and Evaluation: Continue on-going activities.

Fiscal Year 87

Data Processing Systems: Continue on-going activities.

Data Analysis: Continue on-going activities.

Forecasting and Evaluation: Continue on-going activities.

Fiscal Year 88

Data Processing Systems: Continue on-going activities.

Data Analysis: Continue on-going activities.

Forecasting and Evaluation: Continue on-going activities. 


\section{CONCLUSIONS}

An uninterrupted flow of relevant data and timely evaluation of that data constitute the basis of any rational forecasting effort, independent of the object of the forecasts. The prototype operational network as outlined in this report would provide reliable data on appropriate time scales and with minimal density of instruments for earthquake forecasting in those areas of southern California presently understood to have a high probability for large earthquakes. The parameters that will be measured have proven value for prediction and for evaluating the physical processes that control the earthquake cycle. Because of uncertainties intrinsic to earthquake prediction, particular attention must be given to the methods, models and procedures employed for data evaluation.

Factors to consider in weighing the appropriateness of undertaking prototype operational prediction include the potential benefits to be obtained from a successful prediction in southern California, the costs for undertaking operational prediction and the probability of occurrence of the earthquake within a given period of time. The potential benefits from a successful prediction are proportional to possible losses which depend on several variables including the magnitude, location and time of day of the earthquake and the effectiveness of preparedness efforts. Significant reduction to loss of life (up to 14,000) and loss of property (up to 17 billion dollars) could be achieved by a successful prediction. Calculations for the present probability of occurrence for a large to great earthquake (M 6.75-8.00) in southern California yield probabilities in excess of 90 percent that such an earthquake will occur within the next 20 years. The probability for a very large to great earthquake $(M 7.5-8.0)$ is conservatively estimated to be 58-70 percent with in the next 30 years.

Other important considerations that have a bearing on evaluating the desirability of undertaking operational prediction are the research benefits to be obtained from the data generated by the system, development of the capability and experience for operational prediction within the Nation for application elsewhere in the United States and the focussing of attention on disaster mitigation and planning activities in southern California. On the latter point Richard Andrews, Executive Director of the Seismic Safety Commission of the State of California states: "The primary goal of preparedness is life safety; the development of an operational earthquake prediction system will contribute toward achieving that goal, perhaps in a dramatic way. Even if the prediction effort is unsuccessful in providing a short-term warning, the planning done for short-term response to an earthquake alert carries over directly into response to an unpredicted event. The effort to predict, in and of itself helps stimulate preparedness." (Andrews, 1982).

Some earthquakes have been successfully predicted in various parts of the world, but it cannot be stated with certainty that the prototype network described here will successfully predict the next great earthquake in southern California. In the absence of an unforseen research breakthrough, resolution of uncertainties pertaining to reliable earthquake prediction may require many years of research and data collection at the present level of effort. In the 
interim it can be stated with assurance that some earthquakes are predictable given an adequately designed measurement system and analysis strategy and that a disasterous earthquake in southern California may occur before present uncertainties are resolved. Immediate development of an operational prototype system warrants serious consideration in view of the high level of the hazard in southern California, the long lead times required to install a viable operational system and the significant benefits to be derived from such a system.

\section{ACKNOWLEDGEMENTS}

The plans, concepts and strategies summarized in this report evolved in 1 arge part from the informal contributions of numerous individuals and groups that have participated in the Earthquake Hazards Reduction Program. William Ellsworth, Allan Lindh and Mark Zoback provided material and advice that contributed to the preparation of this report. Jerry Eaton, John Filson, and Robert Wallace read early drafts and offered many useful suggestions. 


\section{REFERENCES}

Andrews, R., 1982, Earthquake prediction and preparedness in southern

California, science and public policy, 1982, paper presented to the 1982 Annual Meeting of the Seismological Society of America, in press.

Algermissen, S.T., D.M. Perkins, P.C. Thenhaus, S.L. Hanson, and B.L. Bender, 1982, Probabilistic estimates of maximum acceleration and velocity in rock in the Contiguous United States, U. S. Department of the Interior, Open File Report \# 82-1033, 99p.

Elisworth, W.L., A.G. Lindh, W.H. Prescott and D.G. Herd, 1981, The 1906 San Francisco earthquake and the seismic cycle, Ewing Symposium, Maurice Ewing. Series, 4, 126-140.

FEMA, 1980, An as sessment of the consequences and preparations for a catastrophic California earthquake: findings and actions taken, Federal Emergency Managment Agency, 59p.

Lindh, A.G., 1983, Preliminary as sessment of long-term probabilities for large earthquakes along selected fault segments of the San Andreas fault system in California, U. S. Geological Survey, Open File Report 83-63, $15 p$.

Mogi, K., 1981, Seismicity in western Japan and long-term earthquake forecasting, Ewing Symposium, Maurice Ewing Series, 4, 43-52.

Nishenko, S.P., and W.R. McCann, 1981, Seismic potential for the world's major plate boundaries, Ewing Symposium, Maurice Ewing Series, 4, 20-28.

Sieh, K., 1981, A review of geological evidence for recurrence times of large earthquakes, Am. Geophys. Un., Maurice Ewing Monogr., 4, 181-207. 